\title{
Reaction of Broccoli to Isolates of Verticillium dahliae from Various Hosts
}

\author{
R. G. Bhat and K. V. Subbarao, Department of Plant Pathology, University of California, Davis, c/o U.S. Agri- \\ cultural Research Station, 1636 E. Alisal St., Salinas, CA 93905
}

\begin{abstract}
Bhat, R. G., and Subbarao, K. V. 2001. Reaction of broccoli to isolates of Verticillium dahliae from various hosts. Plant Dis. 85:141-146.

Isolates of Verticillium dahliae from 15 different hosts and V. albo-atrum from alfalfa were tested for their ability to cause wilt on broccoli using a root-dip inoculation method. None of the isolates caused vascular discoloration in broccoli except those from cabbage and cauliflower that were weakly pathogenic. Broccoli cultivars Baccus, Greenbelt, Parasol, Patriot, and Symphony showed resistance to Verticillium infection. Re-isolated strains from fresh samples of internally discolored broccoli and cauliflower root tissues were unable to cause disease symptoms on re-inoculation of broccoli, but caused severe disease on cauliflower. Inoculation of 5-, 7-, 9-, or 11-week-old plants did not alter the resistance in broccoli or the susceptibility in cauliflower against Verticillium. Immunity of broccoli against infection by isolates of $V$. dahliae from non-crucifer hosts, its resistance against crucifer isolates, and as previously described, attrition of $V$. dahliae microsclerotia in soil by broccoli residue, coupled with its importance as a commercial vegetable, make broccoli an attractive rotation crop for the management of Verticillium wilt in many cropping systems.
\end{abstract}

Many species of Brassica are commercially grown as vegetables and oilseeds in different parts of the world. Crucifers are increasingly being recommended as rotation crops $(13,14,28,32,34)$ to control soilborne pathogens in several cropping systems. Members of Brassicaceae have been shown to possess varying degrees of biocidal activity as green manures and soil amendments $(1,19,20,28)$. During tissue decomposition, the glucosinolates in crucifer crops break down to produce sulfides, isothiocyanates, thiocyanates, and nitriles that have either fungistatic or fungicidal properties (9). The term biofumigation has gained greater currency to describe this phenomenon in recent years.

Although crucifer crops contain glucosinolates, they themselves are susceptible to many plant pathogens. Vascular wilt caused by Verticillium dahliae Kleb. is an important disease problem on many plant species, including many Brassica species. Bok choy (Brassica chinensis L.), broccoli raab (B. rapa L.), brussels sprouts (B. oleracia L. var. gemmifera DC), cabbage ( $B$. oleracia var. capitata L.), cauliflower ( $B$. oleracia var. botrytis L. subvar. cauliflora DC.), Chinese cabbage (B. pekinensis (Lour.) Rupr.), and rapini (B. oleracia var. italica Plenck.) are susceptible to $V$. dahliae $(4,6,12,30)$, as are black mustard $(B$.

Corresponding author: K. V. Subbarao

E-mail: kvsubbarao@ucdavis.edu

Accepted for publication 9 October 2000.

Publication no. D-2000-1120-04R

(C) 2001 The American Phytopathological Society nigra (L.) W. Koch), Indian mustard ( $B$. juncea (L.) Czernj. \& Cross.), oilseed rape (B. napus L.), and turnip (B. campestris L.) (36). Resistance to $V$. dahliae is reported in some Brassica spp., but is highly variable $(15,35)$.

Unlike cauliflower and other crucifers, broccoli (B. o. var. botrytis L. subvar. cymosa Lam.) crops have not suffered losses from Verticillium wilt, even in fields heavily infested with $V$. dahliae (16). Artificial inoculations in the greenhouse showed that isolates of $V$. dahliae from cauliflower were weakly pathogenic on broccoli (30). In-depth studies to exploit this phenomenon for Verticillium wilt control in the laboratory and greenhouse revealed that adding fresh broccoli residue amendments to $V$. dahliae-infested soil resulted in significant reductions of soilborne microsclerotia, and reduced incidence of Verticillium wilt on cauliflower (31). Field studies have shown that incorporating broccoli residues into the soil reduces Verticillium wilt on cauliflower $(32,34)$ and lettuce drop caused by Sclerotinia minor (29). Reductions in the numbers of soilborne microsclerotia of $V$. dahliae and incidence of wilt on cauliflower were comparable to reductions caused by chloropicrin and metham sodium treatments (32). Overall reduction in the number of propagules in $V$. dahliaeinfested plots after two broccoli crops was approximately $94 \%$, in contrast to the fivefold increase in the number of propagules after two cauliflower crops (34).

To facilitate greater adaptation of rotations with broccoli in other crops susceptible to $V$. dahliae, the reaction of broccoli to isolates from other hosts should be determined. Although isolates of $V$. dahliae from cauliflower and cabbage are weakly pathogenic to broccoli (30), the pathogenicity of isolates from other hosts to broccoli is not known, nor is it known if broccoli cultivars differ in their reaction to $V$. dahliae. Furthermore, previous studies have not determined the effect of plant age at inoculation on the reaction of broccoli to isolates of $V$. dahliae $(16,30)$. Therefore, the objectives of this study were to determine the pathogenicity of isolates of $V$. dahliae from various hosts on broccoli cultivars, to determine the effect of seedling age at inoculation with $V$. dahliae on growth and infection of cultivars of broccoli and cauliflower, and to re-isolate strains of $V$. dahliae from inoculated cauliflower and broccoli plants and test their pathogenicity on cauliflower and broccoli.

\section{MATERIALS AND METHODS}

Isolates and host plants. Isolates of $V$. dahliae from various hosts and $V$. alboatrum from alfalfa were collected from different locations in California and other parts of the United States (Table 1). Identities of all single-spore isolates of $V$. dahliae were confirmed $(3,30)$ on the basis of colony morphology, conidiophore formation, conidial production, and the presence of microsclerotia. Isolates were maintained on potato dextrose agar (PDA) slants in a refrigerator at $4^{\circ} \mathrm{C}$. Seeds of individual crucifer crops were obtained from seed companies for use in pathogenicity tests.

Effects of isolates of $V$. dahliae on broccoli and cauliflower. Pathogenicity of isolates of $V$. dahliae from artichoke, bell pepper, cabbage, cauliflower, chili pepper, cotton, eggplant, lettuce, mint, potato, strawberry, tomato, and watermelon, and a $V$. albo-atrum isolate from alfalfa was determined on broccoli (cv. Patriot) and cauliflower (cv. White Rock) using the root-dip method described by Koike et al. (16). Seeds were sown into autoclaved riverbed sand in seedling trays and maintained on benches in a greenhouse until inoculation. Inoculum was prepared from cultures of $V$. dahliae grown on PDA plates at room temperature for 1 month, and the conidial density was adjusted to approximately $10^{7}$ conidia $\mathrm{ml}^{-1}$. Four-week-old plants were removed from the seedling trays and $2 \mathrm{~cm}$ of roots from the tip were trimmed just before inoculation. Trimmed or intact roots do not affect the plant reaction (16). Ten plants of each cultivar were inoculated by dipping the roots in a conidial suspension at least for $5 \mathrm{~min}$ and planting them individually into autoclaved 
sand in 12-cm-diameter pots. Roots of 10 plants of each host were trimmed, dipped in sterile distilled water, and maintained as noninoculated controls. Plants were arranged in a random block design on greenhouse benches. All plants were irrigated daily, and fertilizer was applied once in 2 weeks. Growth parameters such as plant height, root and shoot dry weights, and vascular discoloration were recorded 6 weeks after inoculation.

After a 6-week incubation all plants were gently uprooted and washed free of sand. The longitudinally cut crown and main root segment of each plant was visually rated for vascular discoloration. A scale of 0 to 4 was adopted to assess disease severity and wilting: $0=$ no vascular discoloration, $1=1$ to $25 \%$ vascular area discolored, $2=26$ to $50 \%$ discolored, $3=$ 51 to $75 \%$ discolored, and $4=76$ to $100 \%$ discolored with or without foliar wilting. Growth parameters such as plant height above the soil surface and root and shoot dry weights were recorded for each plant. This experiment was performed twice.

In a separate experiment, broccoli cultivars Baccus and Greenbelt were inoculated using the root-dip technique described above with isolates from cauliflower (9001, 90-02), chili pepper (91-03), and tomato (MD-06). Plants treated with water at the time of transplanting served as control. Eight weeks after inoculation, plant heights above the soil line were recorded. Plants were then uprooted, washed free of sand, and longitudinally cut open at the crown and main root region to look for vascular

Table 1. Verticillium isolates used in this study with their hosts and geographical locations

\begin{tabular}{|c|c|c|}
\hline Isolate $^{\mathrm{a}}$ & Host & Geographical location \\
\hline $90-01$ & Cauliflower (Brassica oleracia var. botrytis L.) & California \\
\hline $90-02$ & Cauliflower (Brassica oleracia var. botrytis L.) & California \\
\hline $90-02 \mathrm{BR}^{\mathrm{c}}$ & Broccoli (Brassica oleracia var. botrytis L.) & California \\
\hline $90-02 \mathrm{CF}^{\mathrm{c}}$ & Cauliflower (Brassica oleracia var. botrytis L.) & California \\
\hline $91-03$ & Chili Pepper (Capsicum аппиит L.) & California \\
\hline 91-04 & Artichoke (Cynara scolymus L.) & California \\
\hline $91-05$ & Cabbage (Brassica oleracia var. capitata L.) & California \\
\hline $028 \mathrm{VD}$ & Potato (Solanum tuburosum L.) & Idaho \\
\hline VdCa.59 & Bell Pepper (Capsicum аппиит L.) & California \\
\hline EggV1 & Eggplant (Solanum melongena L.) & New Jersey \\
\hline MD-05 & Cotton (Gossypium hirsutum L.) & California \\
\hline MD-06 & Tomato (Lycopersicon esculentum Mill.) & California \\
\hline VdL-7 & Lettuce (Lactuca sativa L.) & California \\
\hline VP-1 & Alfalfa (Medicago sativus L.) & Pennsylvania \\
\hline SB1442 & Strawberry (Fragaria $\times$ ananassa Duch.) & California \\
\hline Tomato & Tomato (Lycopersicon esculentum L.) & California \\
\hline OC- $96-3$ & Mint (Mentha $\times$ piperita L. $)$ & Oregon \\
\hline Watermelon & Watermelon (Citrullus vulgaris Schrad.) & California \\
\hline
\end{tabular}

a All were isolates of Verticillium dahliae except VP-1 which was V. albo-atrum.

b Sources were R. M. Davis = MD-06; J. E. DeVay = MD-05; D. R. Fravel = EggV1; T. R. Gordon = 91-03, 91-04 and 91-05; W. D. Gubler $=$ SB1442; K. B. Johnson $=$ OC-96-3; S. T. Koike $=90-01$ and 90-02; B. W. Pennypacker $=$ VP-1; M. L. Powelson $=$ O28VD; R. F. Smith $=$ Tomato and Watermelon; K. V. Subbarao $=$ VdL-7 and VdCa.59.

c 90-02BR and 90-02CF were re-isolated from broccoli and cauliflower plants, respectively, after experimentally inoculated with cauliflower isolate $90-02$.

Table 2. Pathogenicity of Verticillium isolates from various hosts on broccoli (cv. Patriot) 6 weeks after inoculation

\begin{tabular}{llcccc}
\hline Isolate & Original host & $\begin{array}{c}\text { Disease } \\
\text { severity }^{\text {a }}\end{array}$ & $\begin{array}{c}\text { Plant height } \\
(\mathbf{c m})\end{array}$ & $\begin{array}{c}\text { Root dry } \\
\text { weight }(\mathbf{g})\end{array}$ & $\begin{array}{c}\text { Shoot dry } \\
\text { weight }(\mathbf{g})\end{array}$ \\
\hline 90-02 & Cauliflower & 2.6 & 22.1 & 1.9 & 3.1 \\
91-05 & Cabbage & 1.9 & 22.5 & 2.0 & 3.3 \\
OC-96-3 & Mint & 0.8 & 24.5 & 2.3 & 4.2 \\
028VD & Potato & 0.7 & 23.2 & 2.8 & 3.6 \\
91-04 & Artichoke & 0.5 & 24.0 & 2.3 & 3.6 \\
MD-06 & Tomato & 0.5 & 25.9 & 2.1 & 4.1 \\
VdCa.59 & Bell pepper & 0.4 & 24.8 & 2.5 & 4.2 \\
EggV1 & Eggplant & 0.4 & 23.3 & 2.6 & 3.6 \\
Watermelon & Watermelon & 0.4 & 24.7 & 1.9 & 3.8 \\
VP-1 & Alfalfa & 0.3 & 25.4 & 2.6 & 4.0 \\
SB1442 & Strawberry & 0.2 & 24.4 & 2.4 & 3.6 \\
91-03 & Chili pepper & 0.1 & 25.0 & 2.6 & 4.5 \\
MD-05 & Cotton & 0.0 & 25.6 & 3.0 & 4.2 \\
VdL-7 & Lettuce & 0.0 & 24.1 & 2.5 & 3.9 \\
Control & & 0.0 & 24.4 & 2.7 & 4.4 \\
LSD $_{(\mathrm{P} \leq 0.05)}$ & & 0.5 & 1.6 & 0.6 & 0.6
\end{tabular}

${ }^{a}$ Vascular discoloration was rated in each plant with the following scale: $0=$ healthy plants without any vascular discoloration in roots, $1=1$ to $25 \%$ vascular discoloration in roots, $2=26$ to $50 \%$ vascular discoloration in roots, $3=51$ to $75 \%$ vascular discoloration in roots, and $4=76$ to $100 \%$ vascular discoloration in roots with or without wilting of plants.

discoloration. Internal root discoloration in broccoli was rated 0 or 1 for the absence or presence of vascular discoloration, respectively. Plant height, foliar and root symptoms, and root and shoot dry weights were recorded. This experiment was repeated once.

Effect of seedling age at inoculation. To determine if age of plants at inoculation influenced Verticillium wilt incidence or severity, 5-, 7-, 9-, and 11-week-old seedlings of broccoli (cv. Baccus, Parasol, and Symphony) and cauliflower (cv. White Rock) were inoculated with isolate 90-02 of $V$. dahliae following the root-dip inoculation method described above. Growth parameters such as plant height, root and shoot dry weights, and vascular discoloration were recorded 6 weeks after inoculation. This study was conducted twice.

$V$. dahliae from artificially inoculated broccoli and cauliflower plants. To compare pathogenicities of strains of $V$. dahliae re-isolated from broccoli and cauliflower, seedlings of broccoli and cauliflower were inoculated with a cauliflower isolate (9002) as described above. Eight weeks after inoculation, roots of broccoli and cauliflower plants showing vascular discoloration were brought to the laboratory and washed thoroughly in tap water. Discolored areas of samples were cut into approximately $4 \times 4 \times 4 \mathrm{~mm}^{3}$ pieces and surface sterilized with $70 \%$ ethyl alcohol for $10 \mathrm{~s}$ followed by two rinses in sterilized distilled water. Cut pieces were placed on Sorensen's NP-10 semi-selective medium (27) and incubated at room temperature for Verticillium growth. After 3 weeks, several colonies that formed microsclerotia were transferred to fresh PDA plates and singlespored. Two strains from broccoli and cauliflower were labeled 90-02BR and 90$02 \mathrm{CF}$, respectively.

Re-isolated strains 90-02BR and 9002CF along with parental isolate 90-02 were inoculated on both broccoli (Baccus) and cauliflower (White Rock) seedlings. Procedures for inoculation and data collection were similar to those described above. Inoculated seedlings were incubated for 6 weeks on greenhouse benches. This experiment was conducted twice.

Data analyses. Analyses of variance were conducted on plant height, root and shoot dry weights, and wilt severity to determine the effects of different isolates of $V$. dahliae on broccoli and cauliflower. Replications within experiments and repetition were considered random effects. Means were computed for each isolatecultivar combination and comparisons of isolates within a host were made using least significant difference tests $(P \leq 0.05)$. Analyses of variance were also conducted on plant height, root and shoot dry weights, and wilt incidence on crucifer plant species to determine the overall effects of seedling age at inoculation. Means and the corresponding standard errors of the mean for 
each variable were computed for individual cultivars and age at inoculation. Data from experiments on different cultivars of broccoli and re-isolated strains from broccoli and cauliflower were also treated similarly. Based on the host response, isolates were grouped as either pathogenic or nonpathogenic.

\section{RESULTS}

Pathogenicity of $V$. dahliae from various hosts on broccoli. None of the $V$. dahliae and $V$. albo-atrum isolates except those from cauliflower and cabbage were highly pathogenic to broccoli (Table 2). Two isolates of $V$. dahliae did not cause root vascular discoloration whereas nine $V$. dahliae isolates and one $V$. albo-atrum isolate caused trace root infection. Although cabbage and cauliflower isolates caused vascular discoloration in the root, no discoloration in the crown and shoot portions was observed. Symptoms typical of Verticillium wilt such as stunting of plant growth, increased number of smaller leaves, and yellowing of lower leaves were not visible in any inoculated broccoli plants. Height of inoculated plants was not significantly reduced $(P>0.05)$ except in plants inoculated with isolates from cabbage and cauliflower (Table 2). Significant reductions in root dry weight relative to uninoculated control was observed only in plants inoculated with cabbage, cauliflower, tomato, and watermelon isolates, whereas shoot dry weight was reduced by isolates from artichoke, cabbage, cauliflower, eggplant, potato, strawberry, and watermelon (Table 2).

Susceptibility of cauliflower. $V$. dahliae isolates from cauliflower (90-01 and 9002) caused wilt in $100 \%$ of inoculated cauliflower plants (data not shown). The height of inoculated plants was significantly lower relative to uninoculated plants $(P \leq 0.05)$, and diseased cauliflower plants produced more crinkled leaves with lower leaves turning yellow prematurely with

Table 3. Pathogenicity of Verticillium isolates from various hosts on cauliflower (cv. White Rock) 6 weeks after inoculation

\begin{tabular}{llcccc}
\hline Isolate & Original host & $\begin{array}{c}\text { Disease } \\
\text { severity }^{\mathbf{a}}\end{array}$ & $\begin{array}{c}\text { Plant height } \\
(\mathbf{c m})\end{array}$ & $\begin{array}{c}\text { Root dry } \\
\text { weight }(\mathbf{g})\end{array}$ & $\begin{array}{c}\text { Shoot dry } \\
\text { weight }(\mathbf{g})\end{array}$ \\
\hline 90-02 & Cauliflower & 4.0 & 10.9 & 0.6 & 2.3 \\
91-05 & Cabbage & 4.0 & 13.4 & 0.8 & 2.8 \\
Watermelon & Watermelon & 3.0 & 16.2 & 0.9 & 3.4 \\
028VD & Potato & 2.6 & 16.9 & 1.2 & 4.0 \\
Tomato & Tomato & 2.6 & 17.4 & 1.2 & 3.8 \\
VP-1 & Alfalfa & 1.5 & 16.7 & 1.1 & 3.6 \\
VdCa.59 & Bell pepper & 1.5 & 17.5 & 1.2 & 3.7 \\
OC-96-3 & Mint & 1.5 & 18.0 & 1.3 & 3.8 \\
VdL-7 & Lettuce & 0.9 & 17.1 & 1.2 & 3.9 \\
SB1442 & Strawberry & 0.9 & 16.9 & 1.3 & 4.0 \\
91-04 & Artichoke & 0.7 & 16.7 & 1.1 & 3.3 \\
EggV1 & Eggplant & 0.7 & 16.3 & 1.2 & 3.7 \\
MD-05 & Cotton & 0.2 & 17.1 & 1.0 & 3.9 \\
91-03 & Chili pepper & 0.1 & 17.2 & 1.3 & 4.0 \\
Control & & 0.0 & 18.4 & 1.4 & 4.1 \\
LSD $_{(\mathrm{P} \leq 0.05)}$ & & 0.6 & 1.3 & 0.3 & 0.5 \\
\hline
\end{tabular}

${ }^{a}$ Vascular discoloration was rated in each plant with the following scale: $0=$ healthy plants without any vascular discoloration in roots, $1=1$ to $25 \%$ vascular discoloration in roots, $2=26$ to $50 \%$ vascular discoloration in roots, $3=51$ to $75 \%$ vascular discoloration in roots, and $4=76$ to $100 \%$ vascular discoloration in roots with or without wilting of plants. wilt symptoms. Progressive internal discoloration in the vascular area was observed in crowns and leaf petioles. Isolates from cabbage, potato, tomato, and watermelon were also pathogenic on cauliflower as measured by disease severity and reductions in plant height, and root and shoot dry weights (Table 3 ).

Resistance of broccoli cultivars to isolates of $\boldsymbol{V}$. dahliae. Broccoli cultivars, Baccus and Greenbelt, were completely resistant to isolates of $V$. dahliae from cauliflower (90-01 and 90-02), chili pepper (91-03), and tomato (MD-06). Only cauliflower isolate 90-02 was able to cause slight root vascular discoloration in $40 \%$ of inoculated plants in cv. Baccus (Table 4). Plant height, foliar and root symptoms, and root and shoot dry weights of inoculated plants were not significantly different $(P>$ 0.05) from noninoculated plants.

Effects of seedling age at inoculation. Analysis of variance indicated that the results between experiments were consistent, and thus, results from only one experiment are presented. Height of broccoli plants was affected by age of seedlings at inoculation only in cv. Symphony (Fig. 1). Significantly greater $(P \leq 0.05)$ numbers of inoculated broccoli plants showed vascular discoloration than control (Fig. 2) although severity of infection on these plants was low. Yellowing of lower leaves with wilting and premature abscission were observed in cauliflower plants inoculated at all ages after 6 weeks of incubation. More than $75 \%$ of plants had vascular discoloration in cauliflower after inoculation at ages 5, 7, 9, and 11 weeks (Fig. 2), and the discoloration had extended to crown regions and petioles.

Pathogenicity of re-isolated strains of $V$. dahliae on broccoli and cauliflower. Strains 90-02BR and 90-02CF, re-isolated from broccoli and cauliflower, respectively, and cauliflower isolate (90-02) caused slight vascular discoloration in 45 to $70 \%$ of broccoli plants compared with more extensive

Table 4. Effect of Verticillium dahliae isolates on growth and disease severity of broccoli cultivars 8 weeks after inoculation

\begin{tabular}{|c|c|c|c|c|c|c|c|}
\hline \multirow[b]{2}{*}{ Growth parameter } & \multirow[b]{2}{*}{ Broccoli cultivar } & \multicolumn{6}{|c|}{ Isolate } \\
\hline & & 90-01 & $90-02$ & 91-03 & MD-06 & Control & $\operatorname{LSD}_{(P \leq 0.05)}$ \\
\hline \multirow{2}{*}{ Plant height $(\mathrm{cm})$} & Greenbelt & 25.6 & 24.5 & $\mathrm{ND}^{\mathrm{a}}$ & 23.4 & 25.1 & 1.9 \\
\hline & Baccus & 23.9 & 24.3 & 25.8 & 24.1 & 22.0 & 2.4 \\
\hline \multirow[t]{2}{*}{ Shoot dry weight (g) } & Greenbelt & 7.3 & 7.0 & ND & 7.4 & 6.7 & 0.9 \\
\hline & Baccus & 6.7 & 6.3 & 5.9 & 6.6 & 6.6 & 0.8 \\
\hline \multirow{2}{*}{ Root dry weight (g) } & Greenbelt & 2.5 & 2.3 & ND & 4.4 & 2.3 & 1.1 \\
\hline & Baccus & 3.7 & 2.7 & 3.0 & 3.7 & 3.5 & 0.9 \\
\hline \multirow[t]{2}{*}{ Diseased plants ${ }^{\mathrm{b}}$} & Greenbelt & 0.1 & 0.0 & ND & 0.0 & 0.0 & 0.1 \\
\hline & Baccus & 0.1 & 0.4 & 0.0 & 0.1 & 0.0 & 0.3 \\
\hline \multirow[t]{2}{*}{ Foliar symptoms $^{\mathrm{c}}$} & Greenbelt & 0.4 & 0.5 & ND & 0.3 & 0.0 & 0.4 \\
\hline & Baccus & 0.4 & 0.6 & 1.0 & 0.3 & 0.0 & 0.4 \\
\hline \multirow[t]{2}{*}{ Root symptoms ${ }^{\mathrm{d}}$} & Greenbelt & 1.0 & 1.0 & ND & 1.0 & 1.0 & 0.0 \\
\hline & Baccus & 1.0 & 1.0 & 1.0 & 1.0 & 1.0 & 0.0 \\
\hline
\end{tabular}

${ }^{\mathrm{a}} \mathrm{ND}=$ Not determined.

${ }^{\mathrm{b}}$ Proportion of plants with internal root discoloration after each plant was rated with a 0 or 1 for the absence or presence of vascular discoloration, respectively. Mean of two experiments with each consisting of 10 plants.

${ }^{\mathrm{c}}$ Foliar symptom severity was rated on a scale of 0 to 4 in which $0=$ normal plants and $4=$ plants with $\geq 75 \%$ of leaves showing chlorosis.

${ }^{\mathrm{d}}$ Extent of root symptoms was rated on a scale of 1 to 4 in which $1=$ normal appearance and $4=$ extensive browning and reduced ro ot laterals. 
discoloration in 85 to $95 \%$ of cauliflower plants. In addition, severe internal discoloration in root, crown, and shoot portions was observed only in cauliflower (Table 5). Growth parameters in inoculated broccoli plants were not significantly different $(P>0.05)$ from noninoculated control. Nevertheless, significant differences in root dry weight, vascular discoloration, foliar, and root symptoms were observed in cauliflower plants inoculated with all three isolates of $V$. dahliae. Only strains 90-02BR and 90-02 significantly reduced plant height and shoot dry weight in cauliflower (Table 5).
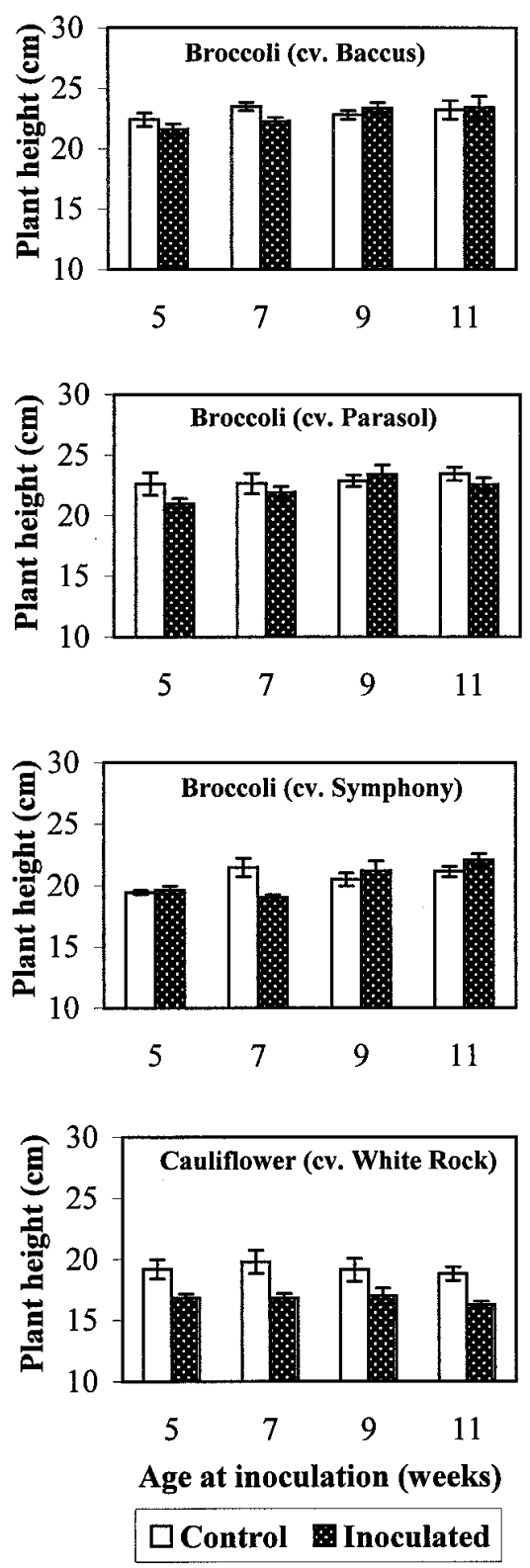

Fig. 1. Effect of isolate 90-02 of Verticillium dahliae from cauliflower on plant heights of broccoli and cauliflower after inoculation at different ages. Plant heights were measured 6 weeks after inoculation. Vertical bars represent the standard errors of the mean.

\section{DISCUSSION}

This study demonstrated the resistance of broccoli to isolates of $V$. dahliae from crucifer crops and immunity against a host of isolates from noncrucifer crops. This resistance or immune reaction was altered neither by the seedling age at which they were inoculated nor by the broccoli cultivars tested. In contrast, cauliflower was highly susceptible to isolates of $V$. dahliae from crucifer crops, and seedling age at which they were inoculated did not alter this susceptibility.

The attrition of microsclerotia of $V$. dahliae by broccoli residue $(31,32,34)$ and
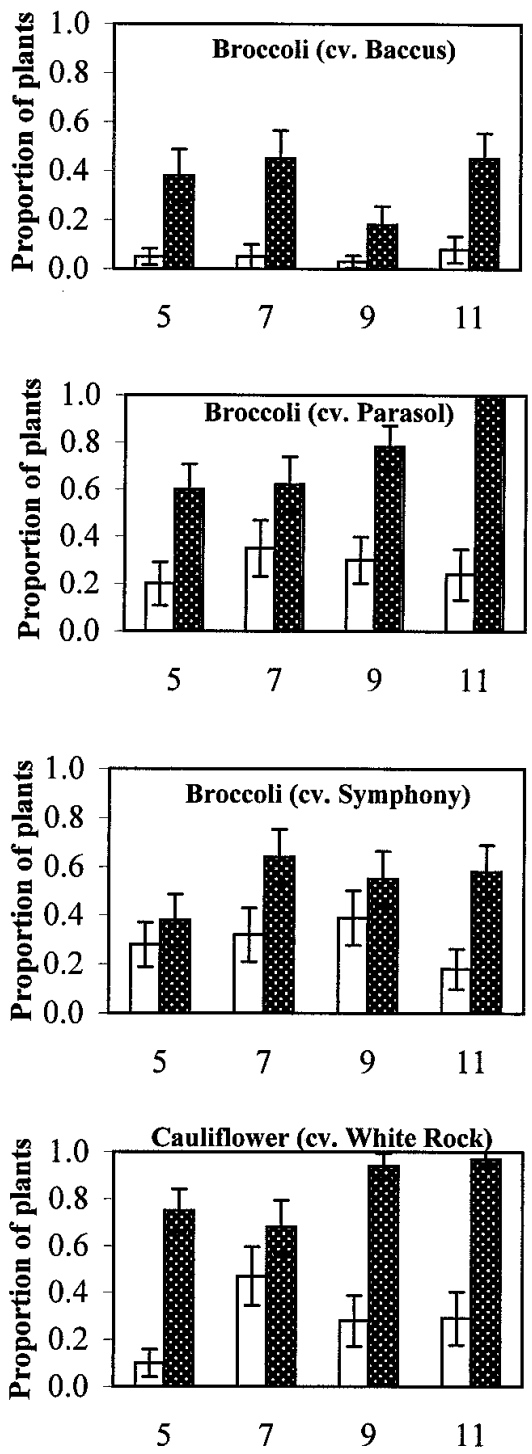

Age at inoculation (weeks) $\square$ Control Inoculated

Fig. 2. Proportion of broccoli and cauliflower plants showing vascular discoloration after inoculation with isolate 90-02 of Verticillium dahliae from cauliflower at different ages. Presence or absence of vascular discoloration was scored 6 weeks after inoculation. Vertical bars represent the standard errors of the mean. a concomitant reduction in the incidence and severity of Verticillium wilt has been previously demonstrated in cauliflower $(32,34)$, and to some extent also in strawberries (26). The initial rationale for undertaking these studies on cauliflower was that Verticillium wilt did not occur in commercial broccoli crops, and that the cauliflower isolate of $V$. dahliae was weakly pathogenic on broccoli $(16,30)$. By determining the reactions of broccoli to isolates of $V$. dahliae from other hosts in this study, we have attempted to show that broccoli is unlikely to augment the soilborne microsclerotia of these isolates when used in rotation with other susceptible crops. However, the feasibility of using broccoli in rotation with crops other than cauliflower and strawberry that are susceptible to $V$. dahliae for Verticillium wilt control remains to be demonstrated.

In contrast to the moderate vascular discoloration in broccoli roots caused by isolates of $V$. dahliae from cabbage and cauliflower, broccoli showed only trace infection at the tip of the root or no infection at all when inoculated with noncrucifer isolates. This unsuccessful colonization of broccoli roots by noncrucifer isolates might be mediated by several factors. Phytotoxic polypeptides and a protein-lipopolysaccharide complex produced by $V$. dahliae $(21,22,23)$ may not be effective in broccoli. Alternatively, constitutive chemicals present in broccoli roots may inhibit the pathogen growth or restrict the progress of the pathogen beyond the foci of infection. Shetty et al. (25) recently characterized root colonization by $V$. dahliae in both broccoli and cauliflower. Despite the absence of wilt symptoms, broccoli root cortex was colonized by $V$. dahliae (25). In this study, even though $V$. dahliae from crucifer crops colonized broccoli roots, and caused internal discoloration, the fungus did not move into the shoot portion and cause perceptible damage to the plants. The discoloration observed in broccoli may be the result of a hypersensitive reaction in response to $V$. dahliae infection. Nevertheless, the nature of resistant and immune reactions of broccoli against crucifer and noncrucifer isolates, respectively, remains to be determined.

Under greenhouse conditions, broccoli plants inoculated with isolates of $V$. dahliae from crucifer crops produce more secondary roots above the soil level (R. Bhat and K. Subbarao, unpublished data). This might help sustain normal growth of broccoli plants despite $V$. dahliae infection. Other anatomical features in the roots may also be involved in conferring resistance to broccoli against $V$. dahliae infection and proliferation $(5,24)$. The resistance or immunity in the host does not limit the establishment of $V$. dahliae on the host surface $(2,8)$ or the root cortex $(10)$. Greater numbers of $V$. dahliae colonies form superficially on resistant than on susceptible 
cotton plants (17). Similarly, more extensive growth of $V$. dahliae and greater numbers of microsclerotia are observed over the surface of immune wheat than on susceptible pea (18). Consistent with these results, isolates of $V$. dahliae from cauliflower colonize the root cortex of broccoli and cauliflower equally well. Formation of microsclerotia, however, is repressed in broccoli (25).

The suppression of the proliferation of $V$. dahliae but not the ascent of the pathogen through conidial movement within the stem appears to be a form of resistance in certain hosts (5). Although crucifer isolates of $V$. dahliae penetrate the cortex and vascular system of broccoli, progression of the disease is limited to the root system. Thus, either the pathogen does not proliferate profusely inside the xylem vessels, or the transport of conidia to various parts of broccoli plants is restricted by vascular coating as observed in resistant tomato plants (24) or both. The noncrucifer isolates of $V$. dahliae to which broccoli is immune, however, may only colonize the cortex and not invade the vascular tissues.

Resistance in broccoli to $V$. dahliae infection is likely to be an active phenomenon because neither the autoclaved broccoli leaves nor the broccoli extract amended through filter sterilization in growth media had any adverse effects on the growth of mycelium and production of microsclerotia by the pathogen (R. Bhat and K. Subbarao, unpublished data).

The exact time of $V$. dahliae infection in different hosts is not known, but the symptoms are usually expressed when the plants reach reproductive stage during which the photosynthetic demand or other stresses on plants are great (33). Even when broccoli is grown in commercial fields with high numbers of microsclerotia of $V$. dahliae, no Verticillium wilt has been observed at any stage of the crop growth. In this study, we attempted to induce the disease on broccoli by inoculating seedlings of broccoli at different ages. Age of plants at inoculation, however, did not alter resistance in broccoli against $V$. dahliae. All three broccoli cultivars inoculated with a cauliflower isolate at 5, 7, 9, and 11 weeks after emergence were equally resistant to $V$. dahliae infection. In contrast, regardless of the seedling age at inoculation, cauliflower plants were susceptible to a similar degree. Resistance to Verticillium wilt in broccoli, therefore, appears to be a stable characteristic.

Previously, Koike et al. (16) had reported that the yellowing of lower leaves and the stunted growth, typically observed in infected cauliflower, were not observed in broccoli plants in commercial fields infested with $V$. dahliae at different locations in California. Even at the time of broccoli harvest, internal discoloration in the vascular tissue was seldom observed. Attempts to re-isolate the pathogen from field plants exhibiting limited vascular discoloration at maturity were unsuccessful (32). Although $V$. dahliae was isolated from discolored roots of young inoculated broccoli plants, mature plants in greenhouse grown in soil infested with a cauliflower isolate of $V$. dahliae neither showed wilt symptoms nor developed microsclerotia on roots (K. Subbarao, unpublished data), validating field observations.

Variation in resistance response to Verticillium infection was limited among broccoli cultivars Baccus, Parasol, Patriot, and Symphony. Isolates of $V$. dahliae and $V$. albo-atrum used in this study were unable to cause wilting and extensive vascular colonization of broccoli plants. This suggests that the characteristic propagule attrition by broccoli residue is likely to be observed regardless of the cultivar planted in rotation with the susceptible crops. Previous field experiments $(32,34)$ have demonstrated the broccoli-mediated propagule attrition in the cauliflower- $V$. dahliae system.

Pathogenicity of re-isolated strains of cauliflower isolate 90-02 from inoculated broccoli (90-02BR) and cauliflower (90$02 \mathrm{CF}$ ) roots was similar to their parental isolates. The commonly observed phe- nomenon of variable pathogenicity through selection and adaptation after passage through hosts $(7,11)$ was not observed in the $V$. dahliae from cauliflower. Resistance in broccoli to isolates of $V$. dahliae from crucifer crops and immunity against isolates from noncrucifer crops is, therefore, likely to be stable.

\section{ACKNOWLEDGMENTS}

This work was supported in part by various California cauliflower growers, the California Lettuce Board, and the California Pepper Commission. We gratefully acknowledge the technical assistance of J. Hubbard, S. Koike, C. Lambert, and M. Orozco. We also thank K. Shetty for comments and criticisms on the manuscript.

\section{LITERATURE CITED}

1. Angus, J. F., Gardner, P. A., Kirkegaard, J. A., and Demarchelier, J. M. 1994. Biofumigation: Isothiocyanates released from Brassica roots inhibit growth of the take-all fungus. Plant Soil 162:107-112.

2. Bell, A. A., and Mace, M. E. 1981. Biochemistry and physiology of resistance. Pages 431486 in: Fungal Wilt Diseases of Plants. M. E Mace, A. A. Bell, and C. H. Beckman, eds. Academic Press, New York.

3. Bhat, R. G., and Subbarao, K. V. 1999. Host range specificity in Verticillium dahliae. Phytopathology 89:1218-1225.

4. Bhat, R. G., and Subbarao, K. V. 1999. Pathogenicity of Verticillium dahliae isolates on plants other than their own hosts. (Abstr.) Phytopathology 89:S7.

5. Brandt, W. H., Lacy, M. L., and Horner, C. E. 1984. Distribution of Verticillium in stems of resistant and susceptible species of mint. Phytopathology 74:587-591.

6. Ciccarese, F., Frisullo, S., and Cirulli, M 1987. Severe outbreaks of Verticillium wilt on Cichorium intybus and Brassica rapa and pathogenic variations among isolates of Verticillium dahliae. Plant Dis. 71:1144-1145.

7. Cunfer, B. M. 1984. Change in virulence of Septoria nodorum during passage through barley and wheat. Ann. Appl. Biol. 104:6168.

8. Evans, G. 1971. Influence of weed hosts on the ecology of Verticillium dahliae in newly cultivated areas of the Naomi valley, New South Wales. Ann. Appl. Biol. 67:169-175.

9. Gamliel, A., and Stapleton, J. J. 1993. Characterization of antifungal volatile compounds evolved from solarized soil amended with cabbage residues. Phytopathology 83:899905.

Table 5. Effect of re-isolated strains of Verticillium dahliae on broccoli (cv. Baccus) and cauliflower (cv. White Rock) 6 weeks after inoculation

\begin{tabular}{|c|c|c|c|c|c|c|}
\hline \multirow[b]{2}{*}{ Growth parameter } & \multirow[b]{2}{*}{ Host } & \multicolumn{5}{|c|}{ Isolate } \\
\hline & & 90-02BR & 90-02CF & 90-02 & Control & $\operatorname{LSD}_{(P<0.05)}$ \\
\hline \multirow[t]{2}{*}{ Plant height $(\mathrm{cm})$} & Broccoli & 21.4 & 20.5 & 20.8 & 20.7 & 1.7 \\
\hline & Cauliflower & 17.3 & 17.6 & 14.0 & 18.2 & 0.9 \\
\hline \multirow[t]{2}{*}{ Shoot dry weight (g) } & Broccoli & 1.1 & 1.1 & 1.2 & 1.2 & 0.2 \\
\hline & Cauliflower & 1.1 & 1.2 & 1.0 & 1.3 & 0.1 \\
\hline \multirow[t]{2}{*}{ Root dry weight (g) } & Broccoli & 0.2 & 0.2 & 0.3 & 0.2 & 0.1 \\
\hline & Cauliflower & 0.1 & 0.1 & 0.1 & 0.2 & 0.0 \\
\hline \multirow{2}{*}{ Diseased plants ${ }^{\mathrm{a}}$} & Broccoli & 0.5 & 0.5 & 0.7 & 0.0 & 0.3 \\
\hline & Cauliflower & 0.9 & 1.0 & 0.9 & 0.0 & 0.1 \\
\hline \multirow[t]{2}{*}{ Foliar symptoms ${ }^{\mathrm{b}}$} & Broccoli & 0.2 & 0.1 & 0.4 & 0.0 & 0.3 \\
\hline & Cauliflower & 3.7 & 3.5 & 2.3 & 0.0 & 0.3 \\
\hline \multirow{2}{*}{ Root symptoms ${ }^{c}$} & Broccoli & 1.2 & 1.4 & 1.2 & 1.2 & 0.4 \\
\hline & Cauliflower & 3.5 & 3.0 & 2.9 & 1.3 & 0.3 \\
\hline
\end{tabular}

a Proportion of plants with internal root discoloration after each plant was rated with a 0 or 1 for the absence or presence of vascular discoloration, respectively. Mean of two experiments, consisting of 10 plants each.

${ }^{\mathrm{b}}$ Foliar symptom severity was rated on a scale of 0 to 4 in which $0=$ normal plants and $4=$ plants with $\geq 75 \%$ of leaves showing chlorosis.

${ }^{c}$ Extent of root symptoms was rated on a scale of 1 to 4 in which $1=$ normal appearance and $4=$ extensive browning and reduced root laterals. 
10. Garber, R. H., and Houston, B. R. 1966. Penetration and development of Verticillium albo-atrum in the cotton plants. Phytopathology 56:1121-1126.

11. Holguin, G., and Bashan, Y. 1992. Increased aggressiveness of Alternaria macrospora, a causal agent of leaf blight in cotton monoculture. Can. J. Bot. 70:1878-1884

12. Isaac, I. 1957. Verticillium wilt of Brussels sprout. Ann. Appl. Biol. 45:276-283.

13. Johnson, A. W., Golden, A. M., Auld, D. L., and Summer, D. R. 1992. Effects of rapeseed and vetch as green manure crops and fallow on nematodes and soil-borne pathogens. J. Nematol. 24:117-126.

14. Keinath, A. P. 1996. Soil amendment with cabbage residue and crop rotation to reduce gummy stem blight and increase growth and yield of watermelon. Plant Dis. 80:564-570.

15. Kemmochi, I., Kobayashi, I., Tsuchiya, M., Sakai, H., and Shimizu, M. 2000. Breeding materials for resistance to Verticillium wilt in Japanese cabbage (Brassica oleracea L. var. capitata). J. Jpn. Soc. Hortic. Sci. 69:483491.

16. Koike, S. T., Subbarao, K. V., Davis, R. M., Gordon, T. R., and Hubbard, J. C. 1994. Verticillium wilt of cauliflower in California. Plant Dis. 78:1116-1121.

17. Lacy, M. L., and Horner, C. E. 1966. Behavior of Verticillium dahliae in the rhizosphere and on roots of plants susceptible, resistant, and immune to wilt. Phytopathology 56:427-430.

18. Levy, J., and Isaac, I. 1976. Colonization of host tissue of varying resistance to Verticillium dahliae. Trans. Br. Mycol. Soc. 67:9194.

19. Lewis, J. A., and Papavizas, G. C. 1971. Effect of sulphur-containing volatile compounds and vapors from cabbage decomposition on Aphanomyces euteiches. Phyto- pathology 61:208-214.

20. Mayton, H. S., Oliver, C., Vaughn, S. F., and Loria, R. 1996. Correlation of fungicidal activity of Brassica species with allyl isothiocyanate production in macerated leaf tissue. Phytopathology 86:267-271.

21. Meyer, R., Slater, V., and Dubery, I. A. 1994. A phytotoxic protein-lipopolysaccharide complex produced by Verticillium dahliae. Phytochemistry 35:1449-1453.

22. Nachmias, A., Buchner, V., and Burstein, Y. 1985. Biological and immunological characterization of a low molecular weight phytotoxin isolated from a proteinlipopolysaccharide complex produced by a potato isolate of Verticillium dahliae Kleb. Physiol. Plant Pathol. 26:43-55.

23. Orenstein, N. J., Tal, M., and Goren, M. 1990. Reactions to a Verticillium dahliae phytotoxin in tissue cultures derived from susceptible and tolerant potato. Plant Sci. 68:123-130.

24. Robb, J., Powell, D. A., and Street, P. F. S. 1989. Vascular coating: A barrier to colonization by the pathogen in Verticillium wilt of tomato. Can. J. Bot. 67:600-607.

25. Shetty, K. G., Subbarao, K. V., Huisman, O. C., and Hubbard, J. C. 2000. Mechanism of broccoli mediated Verticillium wilt reduction in cauliflower. Phytopathology 90:305-310.

26. Shetty, K. G., Subbarao, K. V., and Martin, F. N. 1999. Management of Verticillium wilt in strawberry using vegetable crop rotation. (Abstr.) Phytopathology 89:S72.

27. Sorensen, L. H., Schneider, A. T, and Davis, J. R. 1991. Influence of sodium polygalacturonate sources and improved recovery of Verticillium spp. from soil. (Abstr.) Phytopathology 81:1347.

28. Stapleton, J. J., and Duncan, R. A. 1998. Soil disinfestation with cruciferous amendments and sublethal heating: effects on Meloidogyne incognita, Sclerotium rolfsii and Pythium ultimum. Plant Pathol. 47:737-742.

29. Subbarao, K. V. 1998. Progress toward integrated management of lettuce drop. Plant Dis. 82:1068-1078.

30. Subbarao, K. V., Chassot, A., Gordon, T. R. Hubbard, J. C., Bonello, P., Mullin, R. Okamoto, D., Davis, R. M., and Koike, S. T. 1995. Genetic relationships and cross pathogenicities of Verticillium dahliae isolates from Cauliflower and other crops. Phytopathology 85:1105-1112.

31. Subbarao, K. V., and Hubbard, J. C. 1996. Interactive effects of broccoli residue and temperature on Verticillium dahliae microsclerotia in soil and on wilt in Cauliflower. Phytopathology 86:1303-1310.

32. Subbarao, K. V., Hubbard, J. C., and Koike, S. T. 1999. Evaluation of broccoli residue incorporation into field soil for Verticillium wilt control in cauliflower. Plant Dis. 83:124-129.

33. Xiao, C. L., and Subbarao, K. V. 2000. Effects of irrigation and Verticillium dahliae on cauliflower root and shoot growth dynamics. Phytopathology 90:995-1004.

34. Xiao, C. L., Subbarao, K. V., Schulbach, K F., and Koike, S. T. 1998. Effects of crop rotation and irrigation on Verticillium dahliae microsclerotia in soil and wilt in cauliflower. Phytopathology 88:1046-1055.

35. Yui, S., Ashizawa, H., and Yamagishi, H 1985. New soil borne disease of Chinese cabbage caused by Verticillium dahliae Klebahn, and the resistance in Brassica campestris. Cruciferae Newsl. 10:106-107.

36. Zeise, K., and Buchmuller, M. 1997. Studies on the susceptibility to Verticillium dahliae Kleb. var. longisporum Stark of six related Brassica species. J. Plant Dis. Prot. 104:501 505. 